\title{
DRIED BLOOD SPOT TEST FOR HIV EXPOSED INFANTS AND CHILDREN AND THEIR ANTI-RETRO VIRAL TREATMENT STATUS IN SELECTED HOSPITALS IN ETHIOPIA
}

\author{
Beyene Wondafrash $^{1}$, Desta Hiko
}

\begin{abstract}
BACKGROUND: Infants and children living with HIV receive antiretroviral treatment often late, are exposed to opportunistic infection and quickly develop AIDS. Few hospitals are providing ART service after Dried Blood Spot (DBS)test.The objective of this study is to assess the status of infants and children linked to ART.

METHODS: Descriptive cross-sectional study was conducted in hospitals. Data of 138 infants and children exposed to HIV were collected from registration books and data bases from 2009 to 2011. Data were analyzed using SPSS version 16. Chi-squared test and p-value were computed. In-depth interviews were conducted with key informants.

RESULT: Ninety-eight (71\%) infants and children exposed to HIV were diagnosed for HIV infection of which 68(69.4\%) initiated ART. Twenty four (35.3\%) initiated ART one month after HIV screening results. Thirty-three (50.0\%) and 23(35.3\%) infants and children dropped from and adhered to ART respectively. Eleven (16.2\%) of them who initiated ART died within the study period. HIV infection status ( $p$-value=0.003), dropping from ART ( $p$-value=0.002) and death after ART initiation ( $p$ value $=0.010)$ showed significance with mothers' PMTCT service status.

CONCLUSION: Seven in ten HIV-exposed infants and children were diagnosed with HIV, and almost all of them initiated ART. The overall turnaround time was 10 days. Based up on mothers' PMTCT service status, there was a significant difference among HIV-exposed infants and children in acquiring $H I V$ infection from mothers during pregnancy ( $p$-value $=0.003$ ) and dropping from $A R T$ (p-value=0.010). There were challenges in sample collection and transportation. Early HIV screening during pregnancy and PMTCT service should be strengthened.
\end{abstract}

KEYWORDS: Dried Blood Spot, HIV-exposed infants and children, ART treatment status

DOI: http://dx.doi.org/10.4314/e jhs.v26i1.5

\section{INTRODUCTION}

Children bear a heavy burden of HIV infection $(1,2)$. In 2009 alone, 370,000 infants and children were newly infected of which 260,000 died. Children make up approximately of 7 percent of the total number of people living with HIV worldwide. In the same year, fewer than 200,000 children living with HIV received antiretroviral treatment. Further, those on Highly Active AntiRetroviral Treatment (HAART) often receive it too late for the median age of five and nine years old (2).
Globally in 2009, there were 33.3 million adults and children estimated to live with HIV/AIDS. Two and half million were infants and children living with HIV/AIDS of which approximately 90\% were in sub-Saharan Africa. When infants and children with HIV are failed to take HAART, half of them will be die by the age of two years and three fourth will die within five years (1). HIV testing from DBS using DNA PCR testing makes a definitive diagnosis in children below 18 months. This solves confusion of HIV test with persistence of maternal antibodies until

\footnotetext{
${ }^{1}$ Department of Population and Family Health, Jimma University, Jimma, Ethiopia

${ }^{2}$ Depatement of Epidemiology, Jimma University, Jimma, Ethiopia

Corresponding Author: Beyene Wondafrash, Email: beyenewondafrash@gmail.com
} 
this age (3). In Ethiopia, by January 2009, Early Infant Diagnosis (EID) began in 58 hospitals and 23 health centers. In the same year, the number of infants and children tested almost doubled from 692 to 1340. Infants and children referred from PMTCT (Prevention of Mother to Child Transmission) and ART clinics, over the age of six weeks and below 12 months, and at some sites, below 18 months were tested (2). Despite these efforts, there still are challenges such as limited access to EID, limited trained staff, very few sample collection facilities, inadequate transportation and poor sample storage system, limited number of laboratories capable of performing DNA PCR and few linkages for HIVinfected infants and children to ART clinics (2).

\section{METHODS}

Study design and study participants: A descriptive hospital based cross-sectional study was conducted in 2013 from March to May in two referral hospitals (Jimma University Teaching Hospital and St. Luke Referral Hospital) by giving pediatric Anti-Retroviral Treatments in Ethiopia. The study population included all registered HIVexposed infants and children from records of 2009 to 2011.

Sample size and sampling procedure: In the two hospitals, between 2009 and 2011, there were 150 registered HIV-exposed infants and children whose HIV statuses were identified through DNA PCR by the regional laboratory. Then, study participants were identified at institution level based on set inclusion and exclusion criteria. The inclusion criteria were HIV-exposed infants and children $\leq 18$ months old, who were registered and screened within 2009 to 2011 in two hospitals. Twelve (12) HIV- exposed infants and children with no records on HIV status, treatment and mortality status and turnaround time status from registration book and computer data bases were excluded. As a result, data of only 138 (61 from St. Luke Referral Hospital and 77 from Jimma University Teaching Hospital) exposed infants and children who fulfilled the inclusion criteria were included. These two hospitals were purposively selected based on road accessibility, long and continuous followup of pediatric ART treatment status and availability of long Early Infant Diagnosis (EID) services.
Data collection procedure: Data were collected by trained data collectors from registration books and computer data bases using checklist containing items on socio-demographic characteristics of parents/caregivers, HIV status, treatment status (ART initiation, dropout and adherence status), mortality status and turnaround time. Five in-depth interviews were conducted using unstructured interview guide with with purposively selected key informants from two hospitals (physician and nurse) and a laboratory technologist working at a regional laboratory.

Data processing and analysis: The data were edited and entered in to Epi-data version 3.1 for double entry verification and then transported to SPSS version 16.0 for windows for analysis. The findings were presented using frequency tables and p-values of chi-square tests. Mean and standard deviation were used to present findings of continuous variables. Thematic analysis was done for qualitative data and qualitative findings were triangulated with quantitative findings. Pvalues less than 0.05 were taken as statistical association between variables.

\section{Operational definitions:}

The following operational definitions were used in this study.

Treatment success: Initiation and continuation of HAART, improvement in CD4 count from the baseline, improvement in HIV WHO staging as per the WHO guideline for pediatric HIV treatment

Treatment adherence: Treatment retention (appointment to visit health institution to take medication) and compliance with medication doses (missing not more than three of the prescribed doses for 1 month prior to the study)

Dropouts: Lost to found after initiation of HAART from the two hospitals

Turnaround time: The date from DBS sample collection of HIV-exposed infants and children from two hospitals to the date when HIV screening results from Regional Laboratory were received by two hospitals

HIV exposure: Infants and children who were registered as "HIV-exposed infant and child" by two hospitals

Apparently healthy mother: The HIV positive mother with no recognizable clinical symptoms of HIV. 


\section{Ethical considerations}

Ethical clearance was secured from the Institutional Review Board (IRB) of Jimma University (JU), College of Health Sciences to conduct the study in the specified area. Letter of permission was obtained from JU to communicate with and get permission from hospital managers. The respondents' identities were kept confidential by avoiding identifiers. Written informed consent was obtained from hospital administrative bodies to get permission to take information from registration books. Consent was also obtained from the key informants.

\section{RESULTS}

Socio-demographic characteristics of care givers of HIV-exposed infants and children: One hundred and thirty eight HIV-exposed infants and children in both hospitals were tested for against HIV infection by DNA/PCR. Data of 138 HIV-exposed infants and children and their parents' socio-demographic characteristics were collected. The results indicated that 136(98.6\%) caregivers of the HIV-exposed infants and children were biological parents out of which $130(94.2 \%)$ were females. One hundred and eleven $(80.4 \%)$ caregivers were in the age range of 17 to 35 years, 23(16.7\%) were 36 to 49 years old while $4(2.9 \%)$ were $\geq 50$ years old with the mean age of $30.2(\mathrm{SD}=7.3)$ years (Table 1$)$.

The study also depicted that $103(74.6 \%)$ of the caregivers were married, 13(9.4\%) were single, $9(6.5 \%)$ were divorced and $12(8.7 \%)$ were widowed. Sixty-nine $(50.0 \%)$ caregivers were illiterate, $10(7.2 \%)$ could read and write, $37(26.8 \%)$ while $17(12.3 \%)$ were at primary and secondary educational level respectively. Ninetyfour $(68.1 \%)$ of the caregivers had five and below family members while 44(31.9) of them had above five families members with average family size of 4.55 (Table 1).

The finding of the study also indicated that 104(74.5\%) mothers initiated ART, while they were pregnant with index child. PMTCT service was provided to $81(58.7 \%)$ mothers while they were pregnant with index child. One hundred and sixteen $(84.1 \%)$ mothers were apparently healthy before and during data collection period (Table 1). Turnaround time of screening results of HIVexposed infants and children: Out of 138 infants and children, HIV status of $123(89.1 \%)$ was identified and reported within two weeks of DBS sample collection. The qualitative findings from the Regional Laboratory also showed that DNA/PCR laboratory was equipped with data management system (data clerk and better network), sponsored and supervised by ICAP/Ethiopia.

The overall turnaround was 10 days. One of the in-depth interviewees emphasized that care givers did not appear on the appointment time given during DBS sample collection for result notification. From 138 exposed infants and children, HIV status of $15(10.9 \%)$ was identified and reported after two weeks of DBS sample collection from. One of the interviewees explained that, sometimes, DBS samples from the respective hospitals to the post office were delayed due to absence of assigned persons. The hospitals had poor mechanism to assure whether post offices transported the samples to the Regional Laboratory immediately. The regional laboratory, sometimes, did not check their post offices for arrival of DBS samples.

HIV status of HIV exposed infants and children: Data were collected on 138 HIVexposed infants and children of which $67(48.6 \%)$ and $71(51.4 \%)$ were males and females. From 138 HIV-exposed infants and children, 98(71\%) of them were diagnosed for HIV infection by DNA/PCR. From infants and children diagnosed with HIV,48(49.0\%) and 50(51.0\%) were males and females respectively. Seventy-two $(52.2 \%)$, $59(42.8 \%)$ and $7(5.0 \%)$ HIV-exposed infants and children were below 6 months old, 7-12 months old and 13-18 months old respectively. The mean age of HIV-exposed infants and children was 7.6 $(\mathrm{SD}=3.8)$ months. Thirty-seven (37.8\%), $54(55.1 \%)$ and $7(71.5 \%)$ of the HIV positive infants and children were below 6, 7-12 and 13-18 months old respectively. 
Table 1: Socio-demographic characteristics of caregivers of infants and children, 2009-2011.

\begin{tabular}{|c|c|c|c|}
\hline Variable & & $\begin{array}{c}\text { Number } \\
(\mathrm{n}=138)\end{array}$ & $\begin{array}{l}\text { Percent } \\
(100 \%)\end{array}$ \\
\hline \multirow[t]{2}{*}{ Caregiver } & Biological & 136 & 98.6 \\
\hline & Non-biological & 2 & 1.4 \\
\hline \multirow[t]{3}{*}{ Age in years } & $17-35$ & 111 & 80.4 \\
\hline & $36-49$ & 23 & 16.7 \\
\hline & $\geq 50$ & 4 & 2.9 \\
\hline \multirow[t]{2}{*}{ Sex } & Male & 8 & 5.8 \\
\hline & Female & 130 & 94.2 \\
\hline \multirow[t]{5}{*}{ Occupational status } & Farmer & 48 & 34.8 \\
\hline & Merchant & 28 & 20.3 \\
\hline & Employee & 18 & 13.0 \\
\hline & House wife & 38 & 27.5 \\
\hline & Day laborer & 6 & 4.3 \\
\hline \multirow[t]{5}{*}{ Marital status } & Married & 103 & 74.6 \\
\hline & Single & 13 & 9.4 \\
\hline & Divorced & 9 & 6.5 \\
\hline & Widowed & 12 & 8.7 \\
\hline & Other & 1 & .7 \\
\hline \multirow[t]{4}{*}{ Educational status } & Illiterate & 69 & 50.0 \\
\hline & Read and write & 10 & 7.2 \\
\hline & Primary & 37 & 26.8 \\
\hline & Secondary & 17 & 12.3 \\
\hline \multirow[t]{4}{*}{ Religion } & Muslim & 38 & 27.5 \\
\hline & Orthodox & 63 & 45.7 \\
\hline & Catholic & 3 & 2.2 \\
\hline & Protestant & 34 & 24.6 \\
\hline \multirow[t]{2}{*}{ Family size } & $\leq 5$ & 94 & 68.1 \\
\hline & $\geq 6$ & 44 & 31.9 \\
\hline \multirow[t]{2}{*}{ Was mother on ART } & Yes & 104 & 75.4 \\
\hline & No & 34 & 24.6 \\
\hline \multirow[t]{3}{*}{ Was PMTCT given service } & Yes & 81 & 58.7 \\
\hline & No & 28 & 20.3 \\
\hline & Unknown & 29 & 21.0 \\
\hline \multirow[t]{4}{*}{ Health status of mother } & Apparently healthy & 116 & 84.1 \\
\hline & Ill & 11 & 8.0 \\
\hline & Died & 3 & 2.2 \\
\hline & Unknown & 8 & 5.8 \\
\hline
\end{tabular}

Fifty-three $(64.1 \%)$ HIV-exposed infants and children born from $81(58.7 \%)$ mothers provided with PMTCT service were infected with HIV virus. Seventeen $(60.7 \%)$ HIV-exposed infants and children born from $29(20.3 \%)$ mothers with no PMTCT service were infected with HIV virus, while 28(96.6\%) HIV-exposed infants and children born from $29(21.3 \%)$ mothers with unknown PMTCT service status were infected with HIV virus. The association between the PMTCT service and HIV infection status of infants and children indicated that there was a significant difference among HIV-exposed infants and children in acquiring HIV infection from their mothers depending on PMTCT service status of the mothers during pregnancy $(\mathrm{p}$-value $=0.003)$ (Table 3). 
ART initiation, dropout/adherence and mortality status of HIV diagnosed infants and children: The study indicated that of the infants and children diagnosed to have HIV infection, 68(69.4\%) initiated ART treatment (Table 2). After the reception of DNA/PCR results, 26(38.2\%) infants and children initiated ART within seven days, $18(26.5 \%)$ of them initiated ART within 8 to 30 days and 24(35.3\%) of them initiated ART after 30 days following HIV infection status notification by the hospitals. One of the in-depth interviewees emphasized that care givers did not appear on the appointment time during DBS sample collection for result notification. The association between the PMTCT service and initiation of ART for infants and children diagnosed to have HIV infection indicated no significant difference in ART initiation for infants and children diagnosed HIVpositive based on PMTCT service status of their mothers during pregnancy $(\mathrm{p}$ value $=0.405)($ Table 3).

The study indicated that of the infants and children who initiated ART treatments, 34(50.0\%) dropped from ART treatment (Table 2). The association between the PMTCT service and dropping from ART treatment indicated a significant difference in dropping from ART among infants and children who initiated ART based on PMTCT service status of the mothers during pregnancy (p-value $=0.002)$ (Table 3$)$.

The study also indicated that of the infants and children who initiated ART, 28(80\%) adhered to ART. Eleven $(16.18 \%)$ of the infants and children died after they had initiated ART. The association between the PMTCT service and death after ART was initiated indicated significant difference in death among infants and children who initiated ART based on PMTCT service status of their mothers during pregnancy ( $\mathrm{p}$ value $=0.010) \quad($ Table 2$)$.

Table 2: Treatment and mortality status of HIV diagnosed with infants and children, 2009-2011.

\begin{tabular}{llcc}
\hline Variable & & Number & Percent \\
\hline Age in months & $<6$ & 72 & 52.2 \\
& $7-12$ & 59 & 42.8 \\
\multirow{3}{*}{ Sex } & $13-18$ & 7 & 5.0 \\
& Total & 138 & 100 \\
\multirow{3}{*}{ HIV status } & Male & 67 & 48.6 \\
\multirow{3}{*}{ Was child initiated ART } & Female & 71 & 51.4 \\
& Total & 138 & 100 \\
& HIV+ & 98 & 71.0 \\
Was child dropped ART & HIV- & 40 & 29.0 \\
& Yes & 68 & 69.4 \\
\multirow{3}{*}{ Mortality status } & No & 30 & 30.6 \\
& Total & 98 & 100 \\
& Yes & 34 & 50.0 \\
& No & 34 & 50.0 \\
& Total & 68 & 100 \\
Was child adhered to ART & Yes & 11 & 16.2 \\
& No & 23 & 33.8 \\
& Unknown & 34 & 50.0 \\
& Total & 68 & 100 \\
& Yes & 27 & 79.4 \\
& No & 7 & 20.6 \\
& Total & 34 & 100 \\
\hline
\end{tabular}


Table 3: The relationship between PMTCT service and treatment and mortality status of HIV diagnosed infant and child, 2009-2011.

\begin{tabular}{|c|c|c|c|c|c|c|c|c|}
\hline \multirow[b]{3}{*}{ Variable } & & \multicolumn{6}{|c|}{ PMTCT service provided to mother } & \multirow[b]{3}{*}{ P-value } \\
\hline & & \multicolumn{2}{|c|}{ Yes } & \multicolumn{2}{|c|}{ No } & \multirow{2}{*}{\multicolumn{2}{|c|}{$\begin{array}{cc} & \text { Unknown } \\
\text { Noo } & \text { Percent }\end{array}$}} & \\
\hline & & No & Percent & № & Percent & & & \\
\hline \multirow[t]{2}{*}{ HIV status of infant and child } & $\mathrm{HIV+}$ & 53 & 65.4 & 17 & 60.7 & 28 & 96.6 & 0.003 \\
\hline & HIV- & 28 & 34.6 & 11 & 39.3 & 1 & 3.4 & \\
\hline \multirow[t]{2}{*}{ Child initiated ART } & Yes & 34 & 64.2 & 12 & 70.2 & 22 & 78.6 & 0.405 \\
\hline & No & 19 & 35.8 & 5 & 29.4 & 6 & 21.4 & \\
\hline \multirow[t]{2}{*}{ Child dropped from ART } & Yes & 17 & 50.0 & 11 & 91.7 & 5 & 27.3 & 0.002 \\
\hline & No & 17 & 50.0 & 1 & 8.3 & 17 & 72.7 & \\
\hline \multirow[t]{3}{*}{ Child Mortality status } & Died & 4 & 11.8 & 0 & 0.0 & 7 & 31.8 & $*$ \\
\hline & Alive & 13 & 38.2 & 1 & 8.3 & 9 & 40.9 & \\
\hline & $\mathrm{Uk}^{* *}$ & 17 & 50.0 & 11 & 91.7 & 6 & 27.3 & \\
\hline \multirow[t]{2}{*}{ Child adhered to ART } & Yes & 14 & 82.4 & 1 & 100.0 & 12 & 75.0 & $*$ \\
\hline & No & 3 & 17.6 & 0 & 0.0 & 4 & 25.0 & \\
\hline
\end{tabular}

$*$ Invalid chi-squared test but fisher's exact test p- values $>0.05, * *$ Unknown

\section{DISCUSSION}

This study determined the HIV infection status, dropout, adherence rates and turnaround time among HIV-exposed infants and children. In 2010, in the region where this study was conducted, HIV-positive pregnant women were estimated to be 23,940. From these, annually 3,861 infants were expected to be born with the virus. Focusing on testing efforts only on those known HIVexposed infants and children may result in missed opportunities of HIV screening for truly HIV exposed infants and children (4-7).

This study indicated that $57(42.0 \%)$ of mothers of the infants and children did not take PMTCT. This might be due to lack of awareness among mothers about their HIV status during pregnancy of the index child. This can imply great risk for fetus to acquire HIV infection for mothers who had no ANC followup and did not know their HIV status. HIV-infected mothers who were aware of their own HIV status might not shared their HIV status to pediatric providers (5-8).

Fifty-three (64.1\%) HIV-exposed infants and children born from $81(58.7 \%)$ mothers provided with PMTCT service were infected with HIV virus. Seventeen $(60.7 \%)$ HIV-exposed infants and children born from $29(20.3 \%)$ mothers with no PMTCT service were infected with HIV virus, while 28(96.6\%) HIV-exposed infants and children born from 29(21.3\%) mothers with unknown PMTCT service status were infected with HIV virus. The association between the PMTCT service and HIV status of infant and child indicated that there was a significant difference among HIV-exposed infants and children in acquiring HIV infection from their mother depending on PMTCT service status of the mothers during pregnancy ( $\mathrm{p}$-value $=0.003$ ). Strategies to improve linkage between PMTCT and pediatric records like child health cards indicating maternal HIV status (9) and integrated maternal and child health programs $(10,11)$ are important. If there are no such efforts, many infants and children whose mothers are unaware of their own HIV infections can be missed.

The study indicated that of $98(71 \%)$ infants and children diagnosed HIV-positive by DNA/PCR, ART was initiated for 68 (69.4\%) infants and children. This figure is far higher than the findings in Botswana (12), Tanzania (13) and Malawi (14), which indicated ART was initiated for $45 \%, 46 \%$ and $55 \%$ infants and children with HIV respectively. These differences could be explained by the difference in hospital enrolment rate of infants and children for ART initiation, the study settings and the study samples. The study indicated that there was a significant difference among HIV-exposed infants and children in acquiring HIV infection ( $\mathrm{p}$-value $=0.003)$, dropping from ART (p-value $=0.002)$ and death after ART was initiated ( $\mathrm{p}$-value $=0.010$ ) based on PMTCT service status of their mothers. However, there was no significant difference among HIV- 
exposed infants and children in ART initiation (pvalue $=0.802)$ and adherence to ART (pvalue $=0.405$ ) based on PMTCT service status of their mothers. These two findings could be explained by lack of HIV testing during pregnancy or false negative HIV antibody tests during acute maternal infection (15) or delayed ANC followup during pregnancy of the index child during the study period. These findings are also consistent with the findings of similar studies $(12,16,17,15,18,19)$.

This study had some limitations. Several records were incomplete on required variables in data sources. The size of the study might not represent status of exposed and diagnosed infants and children of all Regional Laboratories in Ethiopia due to limited study sites which might lead to statistical uncertainty. Another limitation of the study was that infants' and children's adherence to treatment through both hospitals was determined using records completed by health providers based on the information provided by mothers of infants and children, and by searching the followup compliance of infants based on their appointment dates. The information gathered from mothers of infants and children might have affected the validity of the study. This might in turn overestimate or underestimate adherence to ART. If the caregivers of infants and children had been directly interviewed and if all clinical markers had been applied, information about treatment adherence would have been more accurate. This study might not also have captured the exposure status of all infants and children of all HIV-positive mothers during antenatal followup.

Despite the limitations explained above, this study identified some valuable facts on ART treatment status, mortality and turnaround time which provide an opportunity for further planning and evidence-based decision-making.

In conclusion, the overall turnaround was 10 days. There was a significant difference among HIV-exposed infants and children in acquiring HIV infection from their mothers and dropping from ART depending on PMTCT service status of the mothers during pregnancy. There was institutional and regional challenges on sample collection, transportation and processing. Successful reduction of new HIV infection during pregnancy, earlier HIV screening during pregnancy and provision of PMTCT service should be effected.

\section{ACKNOWLEDGEMENTS}

We thank Jimma University for funding the study, the administrators of the hospitals, where the study was conducted, for permitting us to use data bases, data clerks for accessing the database in those hospitals and the regional laboratory staffs and other health professionals for their cooperation during the interview.

\section{REFERENCES}

1. Kagaayi J, Gray RH, Brahmbhatt H, Kigozi G, Nalugoda F, Wabwire-Mangen F, et al. Survival of infants born to HIV-positive mothers, by feeding modality, in Rakai, Uganda. PloS One, 2008;3(12):e3877.

2. World Health Organization. HIV and infant feeding: new evidence and programmatic experience-Report of a technical consultation held on behalf of the Inter-agency Task Team (IATT) on Prevention of HIV infections in pregnant women, Mother and their Infants, Geneva: World Health Organization. 2007; Available from: http://whqlibdoc.who.int/publications/200719789241595971_eng pdf

3. Bedri A, Gudetta B, Isehak A, Kumbi S, Lulseged S, Mengistu Y, et al. Extended-dose nevirapine to 6 weeks of age for infants to prevent HIV transmission via breastfeeding in Ethiopia, India, and Uganda: an analysis of three randomised controlled trials. Lancet. 2008;372(9635):300-13.

4. Sherman GG, Matsebula TC, Jones SA. Is early HIV testing of infants in poorly resourced prevention of mother to child transmission programmes unaffordable? Trop Med Int Health TM IH, 2005;10(11):1108-13.

5. Dow A, Dube Q, Chirambo CM, Moore M, Heyderman R, Van Rie A:Abstract no. CDB098. Community based early infant testing and treatment: experience from Blantyre, Malawi 5th IAS Conference on HIV Pathogenesis and Treatment. 2009; Available from: http://www. iasociety.org/Default.aspx?pageId=11\&abstra ctId $=200721828$ 
6. Guay L. SUSS03: Scaling up early infant diagnosis as the bridge between prevention, care, and treatment. International AIDS Society. Vienna. Available from: http://pag.aids2010.org/session.aspx?s=150

7. Kellerman S, Essajee S. HIV testing for children in resource-limited settings: what are we waiting for? PLoS Med, 2010;7(7):e1000285.

8. Rollins N, Mzolo S, Moodley T, Esterhuizen $\mathrm{T}$, van Rooyen $\mathrm{H}$. Universal HIV testing of infants at immunization clinics: an acceptable and feasible approach for early infant diagnosis in high HIV prevalence settings. AIDS Lond Engl, 2009;23(14):1851-7.

9. Mugwagwa R. The Child Health Card as a linkage tool: experiences from Zimbabwe. International AIDS Society. Cape Town, South Africa. 2009; Available from: http://www.docstoc.com/docs/55372155/Issue s-around-pre-test-revised-C

10. Evjen-Olsen B, Olsen OE, Kvåle G. Achieving progress in maternal and neonatal health through integrated and comprehensive healthcare services - experiences from a programme in northern Tanzania. Int $J$ Equity Healthm, 2009;8:27.

11. Hassan AS, Sakwa EM, Nabwera HM, Taegtmeyer MM, Kimutai RM, Sanders EJ, et al. Dynamics and constraints of early infant diagnosis of HIV infection in Rural Kenya. AIDS Behav, 2012;16(1):5-12.

12. Creek T, Tanuri A, Smith M, Seipone K, Smit M, Legwaila K, et al. Early diagnosis of human immunodeficiency virus in infants using polymerase chain reaction on dried blood spots in Botswana's national program for prevention of mother-to-child transmission. Pediatr Infect Dis J, 2008;27(1): 22-6.

13. Kimario CJ, Schimana W, Charles D, Teri IE, Giphart A, Marlinc R,McCullough R, Lee S, VantPadBosch J. Abstract 887, page 79: Scale up of early infant diagnosis (EID) in Tanzania: experience from the Elizabeth Glaser Pediatric AIDS Foundation. The 2009 HIV/AIDS
Implementers' Meeting Windhoek, Namibia. 2009; Available from: http://www.hivimplementers.com/pdfs/ FINALAbstractBook.pdf

14. Braun M, Kabue MM, McCollum ED, Ahmed S, Kim M, Aertker L, et al. Inadequate coordination of maternal and infant HIV services detrimentally affects early infant diagnosis outcomes in Lilongwe, Malawi. $J$ Acquir Immune Defic Syndr, 2011;56(5):e122-128.

15. Kouakou J, Nobah MT, Tanoh A, Fassinou P, Essombo J. Preliminary results of the demonstration phase of routine early HIV testing of HIV-exposed infants and childrenidentified through PMTCT programs in Côte d'Ivoire. AIDS 2008 - XVII International AIDS Conference Mexico City, Mexico. Available from: http://www.aids2008-abstracts.org/ aids2008_book_vol1_web.pdf

16. Lofgren SM, Morrissey AB, Chevallier CC, Malabeja AI, Edmonds S, Amos B, et al. Evaluation of a dried blood spot HIV-1 RNA program for early infant diagnosis and viral load monitoring at rural and remote healthcare facilities. AIDS Lond Engl, 2009;23(18): 2459-66.

17. Khamadi S, Okoth V, Lihana R, Nabwera J, Hungu J, Okoth F, et al. Rapid identification of infants for antiretroviral therapy in a resource poor setting: the Kenya experience. $J$ Trop Pediatr, 2008;54(6):370-4.

18. Menzies NA, Homsy J, Chang Pitter JY, Pitter C, Mermin J, Downing R, et al. Costeffectiveness of routine rapid human immunodeficiency virus antibody testing before DNA-PCR testing for early diagnosis of infants in resource-limited settings. Pediatr Infect Dis J, 2009;28(9):819-25.

19. Nuwagaba-Biribonwoha $H$, Werq-Semo B, Abdallah A, Cunningham A, Gamaliel JG, Mtunga $\mathrm{S}$, et al. Introducing a multi-site program for early diagnosis of HIV infection among HIV-exposed infants in Tanzania. BMC Pediatr, 2010;10:44. 